\title{
RACE AND ENVIRONMENTAL EQUITY
}

\author{
David T. Takeuchi
}

School of Social Work, Boston College

Lisa Sun-Hee Park

Departments of Asian American Studies, Sociology, and Feminist Studies, University of California, Santa Barbara

Yonette F. Thomas

Association of American Geographers

Samantha Teixeira

School of Social Work, Boston College

Aldon Morris' book, A Scholar Denied: W. E. B. Du Bois and the Birth of Modern Sociology (2015), provides compelling biographical, historical, and sociological insights about the influence of W. E. B. Du Bois to the core of social science knowledge. While the science at the turn of the twentieth century explained behavior and social positions with genetic or cultural theories, Du Bois was one of the few scholars who conceptualized and tested ideas about how racial and economic stratification influenced people's social circumstances and lives. Unfortunately, Du Bois's ideas were frequently ignored or dismissed by his peers in the emerging discipline of sociology. Morris notes that even today, Du Bois's theoretical, empirical, and methodological contributions are infrequently discussed in sociology textbooks and courses.

The underappreciation of Du Bois extends to research on the environment. Over the past two decades, a large body of evidence shows that environmental factors are strongly associated with a wide range of social, educational, developmental, psychological, and health outcomes. Du Bois's work is rarely seen as a foundation for this expanding area of research. For example, about a century and a half ago, Du Bois combined archival records, Census statistics, interviews, and observations to examine the social conditions that shaped the behavior and health of Philadelphia residents. The Philadelphia Negro (1899) is a classic study in which Du Bois showed how slavery, unequal economic power, and frayed racial relations strongly influenced crime, educational outcomes, and other social problems.

Du Bois Review, 13:2 (2016) 215-219.

(C) 2016 Hutchins Center for African and African American Research 1742-058X/16 \$15.00

doi:10.1017/S1742058X16000199 
This issue of the Du Bois Review acknowledges and builds on the seminal impact of Du Bois's legacy and presents the range and depth of research on race and environmental equity. The articles are the result of a special call on the topic and the result is a complementary group of papers that address different dimensions of the environmental debate. David N. Pellow leads off this collection by introducing the Critical Environmental Justice Studies framework that shows how corporate and state interests produce ecological forces and agents that have deleterious consequences for Black residents. His paper draws insights from the Black Lives Matter movement and deftly links them to environmental issues.

The next four papers use large-scale datasets to comprehensively address how race is associated with environmental pollutants and risks. Nicole Kravitz-Wirtz and colleagues use a national dataset linked to air pollution data to investigate whether there are racial disparities in pollution exposure in neighborhoods from 1990-2009. Robert J. Sampson and Alix S. Winter center on Chicago to demonstrate that lead exposure is a major pathway between racial segregation and Black disadvantage in the United States. They measure the presence of lead in children's blood from the period 1995 to 2013 and assess whether changes are attributed to individual, household, or environmental factors. Amy J. Schultz and colleagues focus on the Detroit metropolitan area and examine the environmental contaminants that place some neighborhoods at risk. The fourth paper takes a different approach to studying the environment; Stephen P. Gasteyer and colleagues ask, "what is taken-for-granted but not uniformly available to all residents in the U.S?" The authors use U.S. Census data to test whether race is associated with water and sanitation infrastructure.

The next three papers take unique paths to show how people are not passive actors resigned to their environmental circumstances. Karida L. Brown and colleagues use a phenomenological perspective to shed light on how the environment shapes identity and belonging among Black coal miners and their families. As the authors note, their intent is to counter the dominant narrative that "Appalachian people are hopeless, helpless, and homeless; and White." Emily Walton and Mae Hardeback ask critical questions about the promise and problems of neighborhoods that consist of diverse racial and ethnic groups. They do extensive analyses of multiethnic neighborhoods and assess the social factors associated with a sense of community. LeConté J. Dill and colleagues bring forth youth perspectives with a special emphasis on how they understand and respond to housing foreclosures in their neighborhoods.

The final set of papers conducts empirical research on two proposed solutions for environmental risks and exposure: school gardens and parks. Rashawn Ray and colleagues review the promise of school gardens for urban children in shaping educational outcomes. They conduct a series of analyses that assesses whether Washington D.C. schools, with gardens that children tend, produce better achievement outcomes than schools without gardens. Parks have also been suggested as a means to reduce environmental risks and to facilitate better health among residents. Jennifer J. Garcia and colleagues creatively test whether Latino neighborhoods are less likely to have parks than other areas in Los Angeles County.

\section{ADVANCING THE STUDY OF RACE AND ENVIRONMENTAL EQUITY}

Each paper in this issue suggests a few ways that future research can answer the questions raised by the individual studies. In this section, we place these recommendations within the context of a larger research agenda that address the complexities of race and environmental equity. 


\section{The Intersection of Environmentalism with Urban Social and Economic Issues}

In 1991, delegates from the first national People of Color Environmental Leadership Summit convened to forge an alternative direction for the environmental movement. They envisioned an environmentalism that was inclusive of social, racial, and economic justice and defined the environment broadly as "where we live, work, and play" (Alston 1991). Now, more than ever, where we live, work, and play occurs in the cities. About $81 \%$ of the U.S. population resides in urban places and that number is projected to rise (Cohen et al., 2015). The population growth in urban areas is also following new patterns. After a history of decline in the White population in cities, nearly half of the fifty largest cities in the United States saw gains in their White population from 2010 to 2014 (Badger 2015). These changes bring unique challenges for the environmental justice movement.

Urban environmental justice advocates were known for bringing attention to the disproportionate placement of societal 'bads,' including environmental hazards like polluting industries and waste sites, in communities of color. In the past, dense urban areas tended to be populated by lower-income racial and ethnic minorities while those with wealth fled to suburban and rural areas. Now, as upper middle-class Whites and Millennials flock to cities, they are bringing with them a booming interest in sustainability and all things "green." The environmental justice movement now has to contend with protecting neighborhoods of color from undesirable land uses but also with protecting their now desirable urban neighborhoods from displacement. Many see the shift as moving from a reactive approach aimed at preventing 'bads' to a proactive approach of attracting and maintaining environmental 'goods' without displacing people of color.

The next generation of the urban environmental justice movement is beginning to take shape in response to these threats. Environmentalism is viewed through a wider lens that includes housing and the built environment, as well as new areas of focus including healthy food access and food justice, equitable transit access, bicycle and pedestrian safety, access to green space, and anti-gentrification/anti-displacement movements (Martinez-Alier et al., 2016). This current approach to urban environmental justice defines environment widely and looks to promote equity across multiple domains.

The environmental protection and conservation movements, often criticized for their elitist and White perspective, have not traditionally focused on urban environmental issues. William A. Shutkin (2000) aptly noted most Americans care more about protecting secluded distant areas than places where the reside. Novel critical frameworks are addressing this issue and offer promising directions for research on environmental equity, particularly in urban areas. For example, the Just Sustainabilities framework (Agyeman 2013) provides a justice and equity focused understanding of the term sustainability, and urges a move beyond a simplified "green" discourse to one that recognizes the role of social and economic inequality in environmental disparities. David N. Pellow, in this issue, introduces Critical Environmental Justice Studies, which, among other goals, presses scholars to acknowledge intersectionality and attention to the ways intersectional oppression is intertwined with the experience of environmental injustice. These types of theoretical frameworks place value on protecting the urban environment while recognizing that marginalization is multi-faceted and may include oppressions related to race, place, and a variety of social characteristics.

Environmental issues in cities are simultaneously environmental, urban, and social issues. As a means to effectively address the pressing environmental issues of our time, 
from population displacement to climate change, our responses will need to cut across disciplines including the natural and social sciences, law, policy, and the lay-people who bear the brunt of environmental and social inequality. Racial inequality and environmental degradation are closely linked and new iterations of urban environmentalism will need a multi-faceted response that is attentive to these linkages.

\section{Race, Migration, and Climate Injustice}

On a grander scale, John Holdren (2007) argued that "global climate disruption" is more accurate than "global warming" or "climate change" to more fully capture the harm being done to the planet. The terms "global warming" and "climate change" can be misconstrued as moving at a steady, uniform, even, gradual, and benign pace. Support for Holdren's argument is that climate disruptions occur in regions of the world in dissimilar ways. People of color, indigenous communities, and global South nations bear the brunt of climate disruption in the forms of ecological, economic, and health burdens. Climate change may suggest a naturally occurring process, but a disruption refers to conditions created by specific human activities. The concept of climate justice encompasses racial and economic justice as inseparable from any effort to combat climate change. Climate justice recognizes that climate disruption cannot be reversed unless race and economic justice are systematically addressed. Climate justice is a contentious issue because it requires wealthy populations and nations that have contributed the most to the problem take greater responsibilities for solutions.

The mass migration of people, whose lives are uprooted by climate disruptions such as floods, hurricanes, and droughts, is expected to increase over the next two decades (Warner et al., 2009). As mass migration increases, the effects of global inequalities in the distribution of environmental harms will become ever more evident especially for those who will bear the brunt of climate disruptions. Environmental effects will likely affect people and groups seen as different and inferior defined by nation, race, gender, sexuality, and disability. Critical transnational studies on climate migrations are needed to develop a vision for a future characterized by climate justice for all.

\section{Environmental Privilege}

While past empirical studies reveal the hardships and violence associated with environmental inequality, fewer studies consider the flipside of that reality: environmental privilege. Environmental privilege results from the exercise of economic, social, political, and cultural power that some groups enjoy, which enables them near-exclusive access to coveted environmental amenities such as forests, parks, mountains, rivers, coastal property, open lands, and elite neighborhoods. Environmental privilege is based on the premise that some groups can access spaces and resources that are protected from ecological harm; other groups must contend with these harms on a regular basis. Examples of these privileges include organic and pesticide-free foods, neighborhoods with healthier air quality, and energy and other products siphoned from the living environments of other peoples. Lisa Sun-Hee Park and David Pellow (2011) show how environmental privileges accrue to the few while environmental burdens confront the many, including lack of access to quality air, water, and open spaces. If environmental racism and injustice can be easily observed around the world, the same is possible for environmental privilege. Since they are opposite sides of the same coin, one cannot exist without the other. 
Environmental privilege is not simply exclusive access to ecological amenities; it also refers to the maintenance of access and belonging to prized social places, where ecological and non-ecological amenities are a part. Environmental privilege, in the end, is the exertion of power that demarcates where particular people belong. This border-making will come under greater pressure as the effects of climate change increases and the volume of resources-both human and non-human-required to maintain exclusive spaces like resorts intensify. If environmentalism is to become transformative, more basic and applied research must confront the privileges that produce social inequality.

\section{ACKNOWLEDGMENT}

Special thanks to Larry Bobo for his unyielding support of this special issue. Sara Bruya did her usual amazing magic in managing the entire process and production. We recognize the anonymous reviewers who provided helpful commentary and critiques of each paper. We also acknowledge support from R01 HD078501 and the Research in Social, Economic, and Environmental Equity collaborative at the Boston College School of Social Work.

\section{REFERENCES}

Agyeman, Julian (2013). Introducing fust Sustainabilities: Policy, Planning, and Practice. New York: Zed Books.

Alston, Dana (1991). Transforming a Movement. Race, Poverty \& the Environment, 2(3/4): 1-29. Badger, Emily (2015). The White Population is Growing in Many U.S. Cities for the First Time in Years. Washington Post. Wonkblog. <https://www.washingtonpost.com/news/wonk/ $\mathrm{wp} / 2015 / 09 / 24 /$ the-white-population-is-growing-in-many-u-s-cities-for-the-first-time-inyears/> (accessed September 7, 2016).

Cohen, Darryl. T., Geoffrey W. Hatchard, and Steven G. Wilson (2015). Population Trends in Incorporated Places 2000 to 2013. Washington, DC: U.S. Census.

Du Bois, W. E. B. (1899). The Philadelphia Negro: A Social Study. Philadelphia, PA: The University of Pennsylvania.

Holdren, John (2007). Global Climate Disruption: What Do We Know? What Should We Do? A paper presented at the Forum, John F. Kennedy School of Government, Harvard University, November 6.

Martinez-Alier, Joan, Leah Temper, Daniela Del Bene, and Arnim Scheidel (2016). Is There a Global Environmental Justice Movement? The Fournal of Peasant Studies, 43(3): 731-755.

Park, Lisa Sun-Hee, and David Pellow (2011). The Slums of Aspen: Immigrants Versus the Environment in America's Eden. New York: New York University Press.

Shutkin, William A. (2000). The Land that Could Be: Environmentalism and Democracy in the Twenty-first Century. Cambridge, MA: MIT Press.

Warner, Koko, Charles Ehrhart, Alex de Sherbinin, Susana Adamo, and Tricia Chai-Onn (2009). In Search of Shelter: Mapping the Effects of Climate Change on Human Migration and Displacement. Geneva, Switzerland: Care International. 